\title{
Sưsstalinable Chemistry\& Engineering \\ Biocathodic Methanogenic Community in an Integrated Anaerobic Digestion and Microbial Electrolysis System for Enhancement of Methane Production from Waste Sludge
}

\author{
Weiwei Cai, ${ }^{\dagger}$ Wenzong Liu, ${ }^{*}{ }^{\ddagger}$ Chunxue Yang, ${ }^{\dagger}$ Ling Wang, $^{\dagger}$ Bin Liang, ${ }^{\ddagger}$ Sangeetha Thangavel, ${ }^{\dagger}$ \\ Zechong Guo, ${ }^{\dagger}$ and Aijie Wang ${ }^{*} \dagger^{\dagger},+$ \\ ${ }^{\dagger}$ State Key Laboratory of Urban Water Resource and Environment, Harbin Institute of Technology, Harbin 150090, P. R. China \\ ${ }^{\ddagger}$ Key Laboratory of Environmental Biotechnology, Research Center for Eco-Environmental Sciences, Chinese Academy of Sciences, \\ Beijing 100085, P. R. China
}

\section{Supporting Information}

ABSTRACT: Understanding the microbial community structure relative to enhancement of methane production from digestion of waste-activated sludge (WAS) coupled with a bioelectrochemical system is a key scientific question for the potential application of bioelectrochemistry in biogas production. Little has been known about the influence of electrode on the structure and function of microbial communities, especially methanogens in a bioelectrochemical anaerobic digestion $(\mathrm{AD})$ reactor. Here, a hybrid reactor, which coupled bioelectrolysis and $\mathrm{AD}$, was developed to enhance methane recovery from WAS. The methane production rate reached up to $0.0564 \mathrm{~m}^{3}$ methane $/\left(\mathrm{m}^{3}\right.$

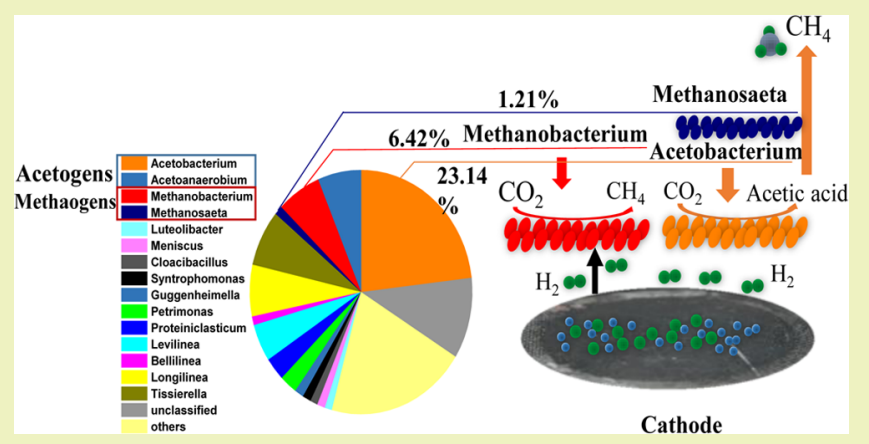
reactor*d) in the hybrid reactor at room temperature, which was nearly double than that of the control anaerobic reactor $\left(0.0259 \mathrm{~m}^{3}\right.$ methane $/\left(\mathrm{m}^{3}\right.$ reactor* $\left.\left.\mathrm{d}\right)\right)$ without bioelectrochemical device. Microbial community analysis revealed that hydrogenotrophic methanogen Methanobacterium dominated the cathode biofilm, which was the predominant contributor to accelerate the methane production rate from WAS. While acetoclastic methanogen Methanosaeta was enriched in the sludge phase of all reactors, shifts of the microbial community structure of the biocathode was in significant correlation with the methane production. This study suggested a potential way to utilize a bioelectrochemical system with the regulated microbial community to enhance methane production from WAS.

KEYWORDS: Bioelectrochemical system (BES), Waste-activated sludge (WAS), Anaerobic digestion (AD), Methanogenic community

\section{INTRODUCTION}

Waste-activated sludge (WAS) is of major technical and economic concern during the treatment process of wastewaters in wastewater treatment plants (WWTPs), and WAS disposal represents up to $50 \%$ of current operating costs. ${ }^{1}$ Anaerobic digestion $(\mathrm{AD})$ is a common process for cost-effective sludge mass reduction due to energy recovery of methane from organics degradation. WAS digestion involves multiple stages including hydrolysis, fermentation, syntrophic acetogenesis, and methanogenesis. Although solubilization and hydrolysis of WAS are considerable limitation steps to eventual organic conversion and energy recovery, the activity of methanogens plays a vital role in the final step of methanogenesis. ${ }^{2,3}$ On the basis of whether $\mathrm{CO}_{2}$ or methyl compounds are utilized as main carbon sources for the methane production, methanogens can be classified into two groups as hydrogenotrophs and methylotrophs. ${ }^{4}$ In general, acetate degradation is one of the rate-limiting steps in most $\mathrm{AD}$ reactors because the mixed functional methanogens (Methanosarcina spp.) prefer to use hydrogen, which has large half saturation coefficient for acetate
(>50-100 mg/L). Moreover, acetoclastic methanogens (Methanosaeta) grow extremely slow (doubling time 5-7 days). ${ }^{5}$ Previous studies indicated that acetoclastic methanogens were generally more sensitive to inhibitory factors than hydrogenotrophic methanogens, such as ammonia concentration, liquid upward velocity, and hydraulic retention time. ${ }^{6-12}$ Hydrogenotrophic methanogens can grow faster (doubling time $4-8 \mathrm{~h}$ ) than acetoclastic methanogens, which was testified with higher growth rates using different substrates (acetate, propionate, butyrate, long-chain fatty acids, glycerol, protein, glucose, and starch). ${ }^{13}$ However, acetoclastic methanogens were finally dominant in most conventional anaerobic conditions. The reason is that hydrogen is required at a low pressure to prevent inhibition of acetogenic bacteria, whereas acetoclastic methanogens take the advantage over hydrogenotrophic methanogens in the methane production. In

Received: June 1, 2016

Revised: July 13, 2016

Published: July 19, 2016 
addition, competition from sulfate-reducing bacteria (SRB), ${ }^{14,15}$ homoacetogens in hydrogen utilization, were considerable inhibitory factors for the growth of hydrogenotrophic methanogens. ${ }^{1}$

Bioelectrochemistry supplies a new pathway for hydrogen evolution from organic compounds, which depends on an electrolysis reaction and microbial catalysts in microbial electrolysis cells (MECs). ${ }^{16,17}$ Typically, an MEC oxidizes organic compounds at the anode in the presence of exoelectrogenic bacteria and transfers electrons and protons to the cathode where protons as electron acceptors boost hydrogen evolution. ${ }^{18}$ However, prior to hydrogen production at the cathode, methane was inevitable to accumulate in the single MEC due to the presence of methanogens at the cathode surface. ${ }^{19}$ The occurrences of $\mathrm{CH}_{4}$ generation from hydrogen and $\mathrm{CO}_{2}$ in the surface of a biocathode have been testified, and most of them were related to hydrogenotrophs. ${ }^{20-22}$ Hence, biocathodes in the MEC can potentially be employed to simultaneously catalyze methane production and stimulate growth of hydrogenotrophic methanogens. Recently, integrated reactors coupling bioelectrochemical system (BES) with $\mathrm{AD}$ were employed to successfully enhance methane production rate and operation stability with hydrogen evolution that finally induced the enrichment of hydrogenotrophic methanogens. $^{23-26}$ Previous studies on methane-producing MECs concentrated on regulating strategy, feasibility, and stability; however, there is still a lack of better understanding of electron recovery evaluation to energy gas conversion in the combined system of $\mathrm{BES}$ and $\mathrm{AD}$, which may change electron flow or electrode respiring communities in $\mathrm{BES}$. $\mathrm{Hu}^{27}$ showed the feasibility and inevitability of methane production in single MECs, providing the insight into the turning point from hydrogen to methane. Jansen ${ }^{28}$ investigated long-term performance for carbon dioxide reduction in methane-producing MEC and showed strong stability for continuously converting $\mathrm{CO}_{2}$ to methane and a promising energy efficiency achieved from current methane production rate. Our previous study also explored the strategy of external voltage optimization for inhibition and enhancement of methane production. ${ }^{29}$ To date, studies showed few insights into the methanogenesis pathway through MEC in AD. The differences in methanogen metabolism activity between hydrogenotrophic and acetotrophic pathways determine the advantageous potential to increase the methane production rate in a hybrid reactor with hydrogenotrophic methanogens over the conventional $\mathrm{AD}$ process where acetotrophic methanogens are commonly dominant. The function and underlying mechanism of the biocathode in the hybrid system with complex substrates like WAS is still poorly understood.

The objective of this study was to evaluate the performance efficiency of a hybrid reactor that coupled MEC with $\mathrm{AD}$ in terms of methane production and organics degradation by employing WAS as the substrate. It was mainly considered the evaluation and calculation of increased methane production that contributed from the bioelectrochemical system rather than the anaerobic process. Therefore, typical batch cycles were chosen to calculate electron conversion to methane generation. During the experiment, the structure of microbial communities of cathode and anode biofilms and sludge were also examined to support the evaluated contribution from $\mathrm{BES}$ to $\mathrm{AD}$.

\section{METHODS AND MATERIALS}

MEC-AD Reactor Construction. Two glass reactors were constructed for methane production from WAS. A cylinder $(7 \mathrm{~cm}$ inner diameter $\times 18 \mathrm{~cm}$ height, total volume of $700 \mathrm{~mL}$ ) was designed, and the WAS was mixed with a stirrer. The anode was a graphite brush $\left(4 \mathrm{~cm}\right.$ diameter $\times 8 \mathrm{~cm}$ length; $\left.1.375 \mathrm{~m}^{2}\right)$, and the cathode comprised carbon cloth (3 cm diameter, YW-50 YiBang; Taiwan) covered with a Pt catalyst layer $\left(0.5 \mathrm{mg} \mathrm{Pt} / \mathrm{cm}^{2}\right)$ on one side. The anode brush was initially enriched in small single chamber MECs, and then a new Pt catalyst cathode was inserted into the glass reactor. The distance between the anode and cathode was $2 \mathrm{~cm}$. External voltage was supplied between the anode and cathode by switching the power source (FDPS-150, Fudantianxin Inc., China) with a fixed voltage of $0.8 \mathrm{~V}$. The effective volume of WAS was $550 \mathrm{~mL}$ (WAS of $500 \mathrm{~mL}+$ inoculation of $50 \mathrm{~mL}$ ); thus, the headspace volume was $150 \mathrm{~mL}$. Biogas was collected in a gas bag (0.5 L capacity; cali-5-bond, Calibrated Instruments, U.S.A.) which was attached on the top of the reactor. A control reactor without electrodes was operated under the same environmental conditions as the hybrid reactor. All reactor operations were conducted at room temperature of $20 \pm 2{ }^{\circ} \mathrm{C}$

Anode Biofilm Enrichment. Two single chamber MECs (SMECs) were constructed with polycarbonate to domesticate the anode biofilm. Each reactor was a cube $(8 \mathrm{~cm} \times 8 \mathrm{~cm})$ with an inner cylindrical chamber of $8 \mathrm{~cm}$ length and $5 \mathrm{~cm}$ diameter and an empty bed volume of $158 \mathrm{~mL}$. A syringe (volume of $10 \mathrm{~mL}$ ) was attached on top of each reactor for the gas collection.

The anode mentioned above was soaked in acetone for $24 \mathrm{~h}$ and heated in a muffle furnace at $450{ }^{\circ} \mathrm{C}$ for $30 \mathrm{~min}$ before anode microbial community enrichment; a carbon cloth coated with $\mathrm{Pt} / \mathrm{C}$ was used as the cathode. Activated sludge (Taiping wastewater treatment plant, Harbin, China) mixed with acetate solution at a ratio of 1:10 was inoculated to start up the reactor. External voltage was fixed at $0.8 \mathrm{~V}$. The SMECs were fed with $158 \mathrm{~mL}$ of sodium acetate, which was 50:50 mixed with $50 \mathrm{mM}$ PBS $\left(\mathrm{Na}_{2} \mathrm{HPO}_{4} 4.58 \mathrm{~g} / \mathrm{L}, \mathrm{NaH}_{2} \mathrm{PO}_{4} \cdot \mathrm{H}_{2} \mathrm{O} 2.45 \mathrm{~g} /\right.$ $\mathrm{L}$, $\mathrm{pH} 7.0$ and nutrient solution, $\mathrm{NH}_{4} \mathrm{Cl} 0.31 \mathrm{~g} / \mathrm{L}, \mathrm{KCl} 0.13 \mathrm{~g} / \mathrm{L}$ ). Once the reactor produced a voltage $>0.10 \mathrm{~V}$ during a fed-batch cycle, the inoculum was replaced. To obtain uniform performance (current and gas production), reinoculation was conducted in some reactors. When all reactors showed similar performance and stabilization with a current of $4 \mathrm{~mA}$, the brush was transferred into an MEC-AD reactor.

Pretreatment and Acidification of WAS. WAS was collected from a secondary sedimentation tank of a municipal wastewater treatment plant in Harbin, China. Sludge was concentrated by settling at $4{ }^{\circ} \mathrm{C}$ for $24 \mathrm{~h}$ and was filtered through a stainless steel sieve $(50$ eyes-screen). Alkali coupled with ultrasonic pretreatment showed high performance in our previous studies. ${ }^{30,31}$ Hence, this method was applied in this study. Ultrasonic pretreatment was performed with $28+$ $44 \mathrm{kHz}$ ultrasonicator (Ningbo Scientz Biotechnology Co., China). ${ }^{31}$ The ultrasonic energy density was $0.5 \mathrm{~kW} / \mathrm{L}$ for $10 \mathrm{~min}$. In the alkali pretreatment, the $\mathrm{pH}$ value of WAS was adjusted to 10 using $4 \mathrm{~mol} / \mathrm{L}$ $\mathrm{NaOH}$. For the bifrequency ultrasonic pretreatment, the highest acidification rate was obtained in 3 days for fermentation as described previously, ${ }^{31}$ hence, the alkali plus ultrasonic-pretreated WAS was hydrolyzed and acidified after inoculation (Taiping wastewater treatment plant, Harbin, China) in all reactors for 3 days, which was followed by the operation of the MEC-AD reactor.

Analytical Methods. The composition of volatile fatty acids (VFAs) was analyzed by using an Agilent 7890 gas chromatography system. ${ }^{32}$ Soluble chemical oxygen demand (SCOD), total chemical oxygen demand (TCOD), carbohydrate(saccharides), and protein were determined as described previously. ${ }^{30}$ Voltage and current were recorded using a multimeter (model 2700; Keithley Instruments, U.S.A.) every $10 \mathrm{~min}$. Gases (hydrogen, $\mathrm{CO}_{2}$, and $\mathrm{CH}_{4}$ ) were analyzed using a gas chromatography system (Fuli GC9790II, Zhejiang Analytical Instrument, Inc., Taizhou China).$^{30}$ The $\mathrm{pH}$ was measured using a $\mathrm{pH}$ meter (PHS-3C, Leici Instrument, Ltd., Shanghai, China).

Microbial Community Analysis. The samples for microbial community analysis were taken at six different time points and positions from both reactors. The sample of source sludge was the 
sludge used as the inoculum of the reactor and feedstock for $\mathrm{AD}$ treatment. The anode startup sample was cut from carbon brush after acclimatization outside and before insertion into the hybrid reactor. Anode and cathode samples were collected at the end of operation in the hybrid reactor. Considering that the attachment of feedstock sludge on the surface of electrodes could affect the analysis for the microbial community in electrode biofilms, carbon brushes of the anode and carbon cloth of the cathode were softly soaked with distilled water for 1-2 min to remove the attached sludge on the surface prior to sampling for microbial community analysis. The MEC-AD reactor and $\mathrm{AD}$ reactor were continuously mixed by magnetic stirrer, and sludge samples were collected from the bottom of the reactors.

Microbial community analysis was performed using the respective samples of raw sludge, anode startup, anode biofilm, cathode biofilm, sludge in the MEC-AD, and sludge in the $\mathrm{AD}$ reactor. Illumina MiSeq sequencing was constructed using bacterial primers $341 \mathrm{~F}$ and $805 \mathrm{R}$ for the V3-V4 region of the $16 \mathrm{~S}$ rRNA gene; moreover, we used $349 \mathrm{~F}$ and 806R for archaea (Figure SI5). The raw sequence data were collected in a Miseq sequencing machine in fastq format. The forward and reverse directions and barcodes were produced into separated files. First, all sequences were assigned to samples according to the barcodes. The forward and reverse reads were merged into full length sequences. The average read length was more than $400 \mathrm{bp}$ after mergence. Chimera detection and removal was completed using UChime. All sequences were clustered using UCLUST software (uclust v1.1.579) at 97\% similarity level, and taxonomic assignment was through the Ribosomal Database Project classifier with minimal 50\% confidence estimates. $^{33}$

Quantitative PCR (qPCR) was employed to analyze the abundances of methyl coenzyme $\mathrm{M}$ reductase ( $m c r A)$ gene for four samples collected from the anode and cathode and sludge in the MEC-AD and $\mathrm{AD}$ reactors. As shown in the Support Information (Figure SI1), the primer used for every sample was described previously.

\section{Calculation.}

Input electric energy efficiency:

$$
\eta_{\text {electricty }}=\frac{\frac{V_{\text {net }}}{V_{\mathrm{m}}} \Delta H_{\text {methane }}}{\int_{t}^{n} U I \mathrm{~d} t}
$$

where $\eta_{\text {electricity }}$ represents the input electric energy efficiency, $V_{\text {net }}$ represents the volume of increased methane production from 1 to $n$ day, calculated by using the accumulated value of MEC-AD minus $\mathrm{AD}$ value. Here, $V_{\mathrm{m}}=22.4 \mathrm{~L} / \mathrm{mol}$ represents the molar volume of gas. Also, $U$ and $I$ represent the external voltage and current value, and $\Delta H_{\text {methane }}=891 \mathrm{~kJ} / \mathrm{mol}^{35}$ All parameters mentioned in the context were under at standard conditions.

Theoretical methane produced from electrons:

$$
V_{\text {methane }}=U I t W_{\text {methane }} V_{\mathrm{m}}
$$

where $V_{\mathrm{m}}=22.4 \mathrm{~L} / \mathrm{mol}$ represents the molar volume of gas and $V_{\text {methane }}$ means the volume of methane produced from electrons. Here, $T=24 \mathrm{~h}$ means 1 day, and $W_{\text {methane }}=4.043 \mathrm{mmol} /$ wh indicates the conversion from electric heat into methane. ${ }^{36}$

\section{RESULTS}

Accelerated Methane Production in MEC-AD Reactor. The MEC-AD reactor was operated in batch mode with electrodes and exhibited considerable performance difference in methane production rate compared to the control reactor without electrodes. After the WAS was pretreated by alkali followed by ultrasonication, the methane yield was low under anaerobic conditions during the first 4 days of its hydrolysis and acidification process. The methane production rate kept increasing from the fifth day when electrons started to flow from anode to cathode; hydrogen was generally detected on the fifth day $(16.25 \mathrm{~mL})$ and sixth day $(8.66 \mathrm{~mL})$. Meanwhile, the control reactor without electrodes exhibited the final stage of methanogenesis with little methane production during the $\mathrm{AD}$ process. Interestingly, the average methane yield in the hybrid reactor was $39.0 \pm 14.0 \mathrm{~mL} / \mathrm{d}$, which was nearly double that of the $\mathrm{AD}$ reactor $(18.1 \pm 9.1 \mathrm{~mL} / \mathrm{d})$ until 18 th day $(P=0.034)$. In phase 1 (from fourth to 18th day), the methane production rate of the MEC-AD (0.0564 $\mathrm{m}^{3}$ methane $/\left(\mathrm{m}^{3}\right.$ reactor* $\left.\mathrm{d}\right)$ ) reactor was higher than the $\mathrm{AD}$ reactor $\left(0.0259 \mathrm{~m}^{3}\right.$ methane/ $\left(\mathrm{m}^{3}\right.$ reactor*d $\left.)\right)$.

As shown in Figure 1A, current value of the MEC-AD apparently dropped on 18th day and gradually declined in the
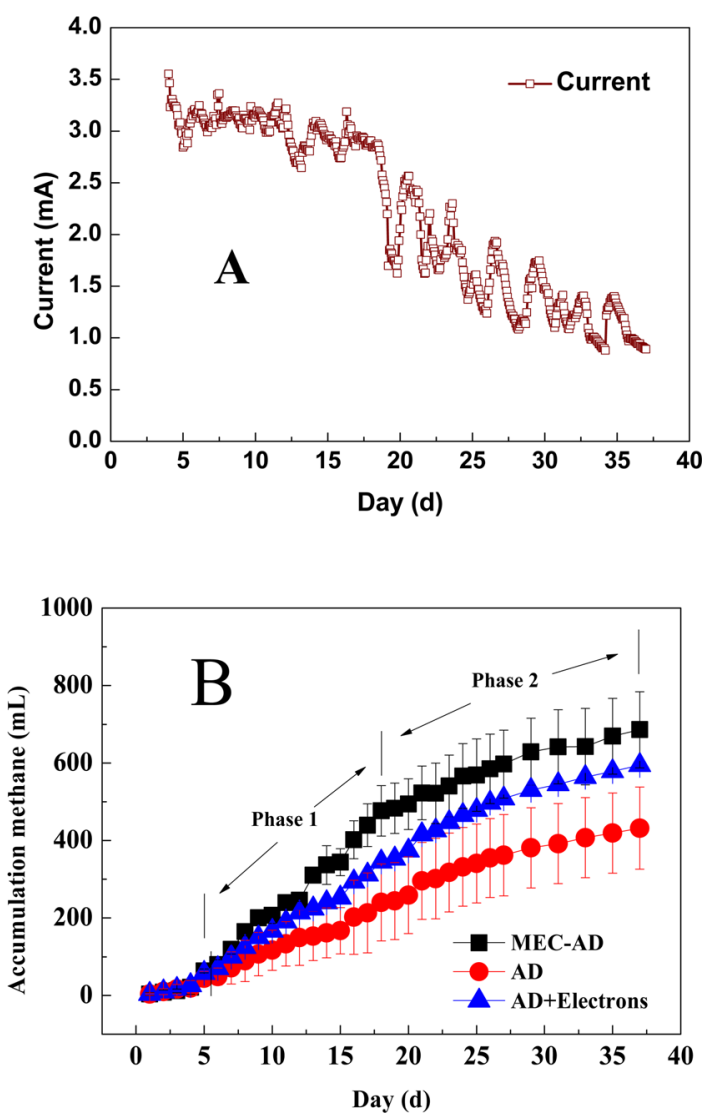

Figure 1. (A) Current change in MEC-AD reactor. (B) Accumulated methane production in MEC-AD and $\mathrm{AD}$ reactors. Electrons contribution was estimated based on current.

phase 2, and the reactor had simultaneously less methane production rate $\left(0.0204 \mathrm{~m}^{3}\right.$ methane $/\left(\mathrm{m}^{3}\right.$ reactor* $\left.\left.\mathrm{d}\right)\right)$. Moreover, the control reactor showed a similar decline trend in the methane production, which was caused by the consumption of organic compounds such as protein, saccharide, and VFAs. Electron contribution was considered to enhance methane yield (Figure 1B). Considering the contribution of electrons to methane yield, the sum of $\mathrm{AD}$ and electrons were calculated from methane produced in $\mathrm{AD}$ (control) and theoretical methane produced from electrons through MECs. The highest methane yield was $0.0387 \mathrm{~m}^{3}$ methane $/\left(\mathrm{m}^{3}\right.$ reactor* $\left.\mathrm{d}\right)$. Besides the electrons contribution, the increase in methane production was slightly higher than that in the $\mathrm{AD}$ in phase 1 .

The major components of WAS, saccharide, protein, and VFAs were released after pretreatment. In batch operation, concentration of saccharide and protein increased to 98 and 
Table 1. Measured Main Characteristics of WAS during Pretreatment, Acidification, and Methanogenesis Stage ${ }^{a}$

\begin{tabular}{|c|c|c|c|c|c|c|c|c|c|c|}
\hline \multicolumn{2}{|l|}{ fraction } & saccharide & Protein & total VFAs & ammonium nitrogen & phosphate & $\operatorname{VSS}(\mathrm{g} / \mathrm{L})$ & TCOD & VSS RE\% & TCOD RE\% \\
\hline \multirow[t]{2}{*}{ pretre-atment } & origin & 8 & 30 & 378 & 144 & 90 & 14 & 15650 & - & - \\
\hline & $\mathrm{U}+\mathrm{A}$ & 98 & 417 & 396 & 225 & 170 & - & - & - & - \\
\hline \multirow[t]{2}{*}{ MEC-AD } & Ac & 102 & 250 & 1433 & 343 & 281 & - & - & - & - \\
\hline & end & 44 & 87 & 175 & 505 & 186 & 7.2 & 9201 & 48.5 & 41.2 \\
\hline \multirow[t]{2}{*}{$\mathrm{AD}$} & Ac & 151 & 253 & 1640 & 735 & 330 & - & - & - & - \\
\hline & end & 49 & 93 & 232 & 631 & 198 & 8.7 & 10025 & 37.9 & 35.9 \\
\hline
\end{tabular}

${ }^{a}$ All units are $\mathrm{mg} / \mathrm{L}$. RE\% represents removal efficiency. U+A represents ultrasonic plus alkali pretreatment. Ac represents acidification process. Symbol “-" represents no data.
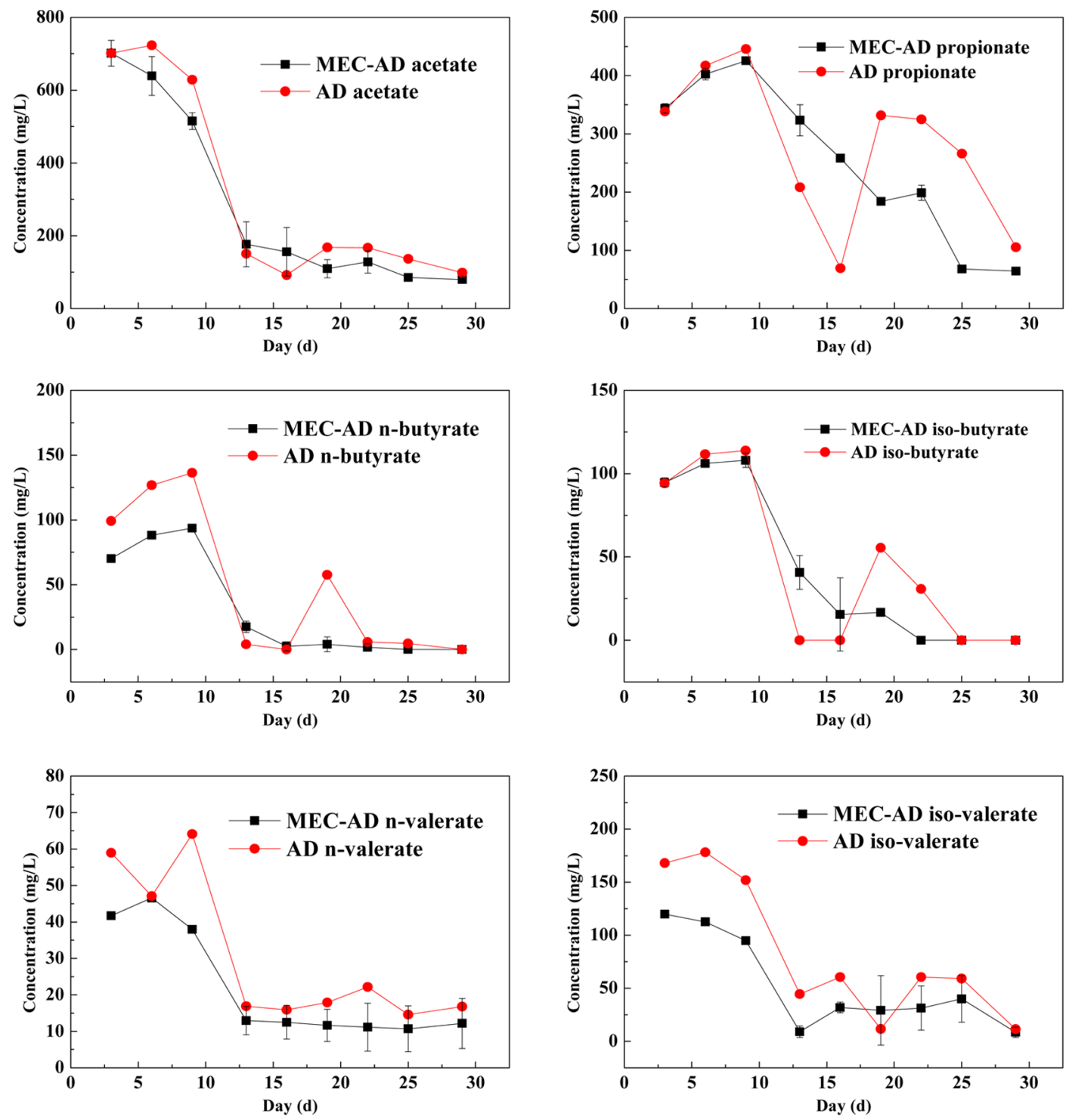

Figure 2. Changes of VFAs including acetic (HAc), propionic (HPr), n-butyric (n-HBu), iso-butyric (i-HBu), n-valeric (n-HVa), and iso-valeric (i$\mathrm{HVa}$ ) acids.

$417 \mathrm{mg} / \mathrm{L}$, respectively, after pretreatment (Table 1 and Figure SI2). The final concentration of saccharide and protein in the MEC-AD was slight lower than that of the $\mathrm{AD}$ reactor (Table 1). In batch operation, the conversion of saccharides and proteins to VFAs were detected, resulting in considerable accumulation of acetate, propionate, n-butyrate, iso-butyrate, nvalerate, and iso-valerate in either MEC-AD or $\mathrm{AD}$ (Figure 2 and Figure $\mathrm{SI} 3$ ). At the end of the $\mathrm{AD}$ process, butyrate and valerate were barely depleted in all reactors. The final concentrations of acetate and propionate in MEC-AD were lower than that of the $\mathrm{AD}$ reactor. In all reactors, there was an obvious increase in the concentration of ammonium nitrogen as the cell wall of microbes was broken during the $\mathrm{AD}$ process. Interestingly, phosphate concentration increased during the whole process and subsequently decreased at the end. Removal efficiency (RE) of VSS in the MEC-AD reached $48.5 \%$, which 

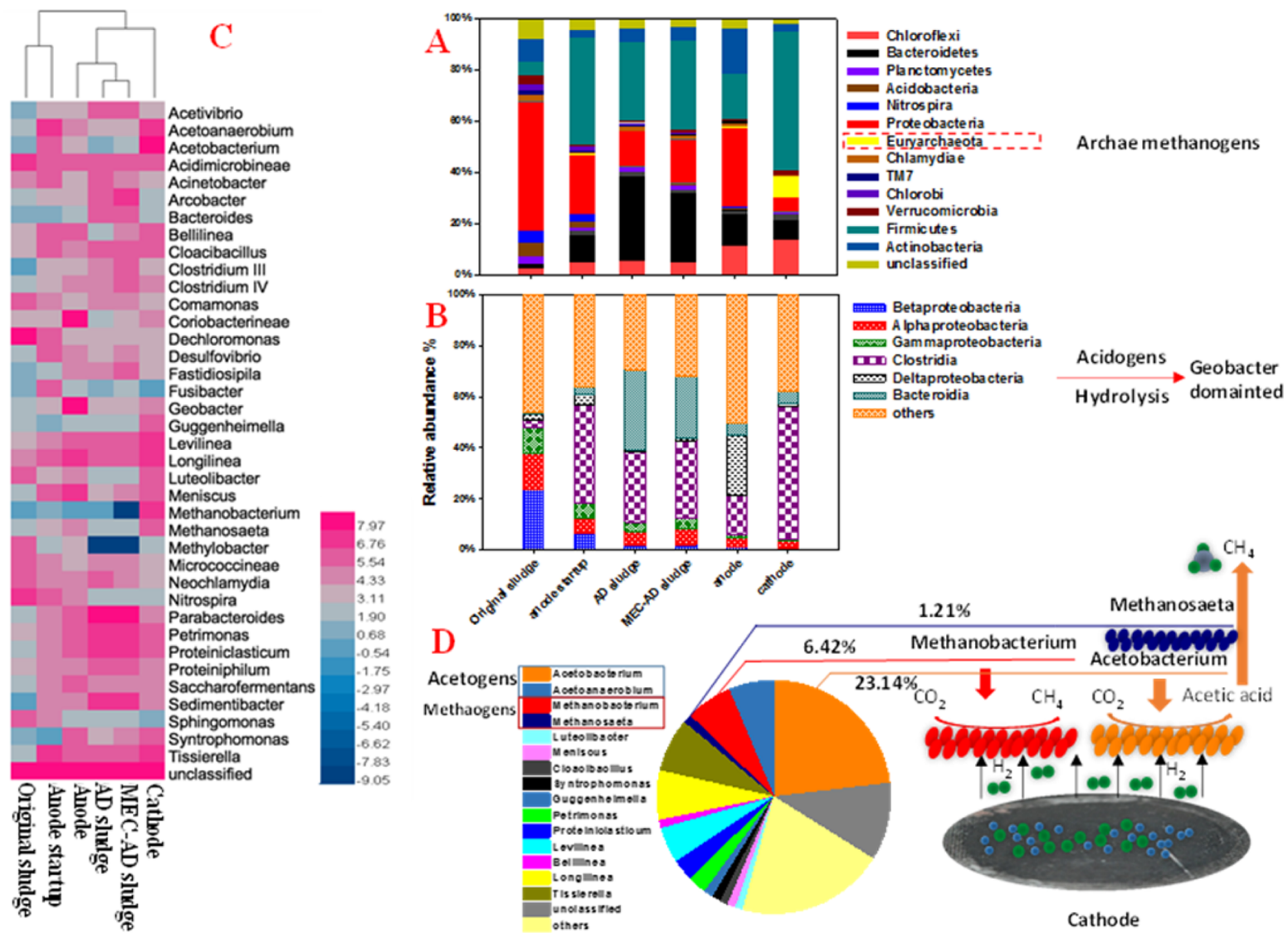

Figure 3. Taxonomic classification of 16s rRNA gene sequences from microbial communities of original sludge, electrode surfaces, and sludge in both reactors at phylum level (A). The distribution of the most dominant class (B). Hierarchical clustering analysis at genus level representing all OTUs present at a relative abundance $\geq 1 \%$ in at least one of samples (C). Distribution of dominant genus (relative abundance $\geq 1 \%$ ) at cathode biofilm and two pathways of methane formation in the surface of electrode was proposed (D).

was obviously higher than that of the $\mathrm{AD}(37.9 \%)$. According to the removal of VSS, the methane yield of MEC-AD was $111.19 \mathrm{~mL} / \mathrm{g}$ VSS that was higher that of $\mathrm{AD}(103.09 \mathrm{~mL} / \mathrm{g}$ VSS). Overall TCOD removal efficiencies were $41.2 \%$ in the MEC-AD, whereas only $35.9 \%$ were obtained in the $\mathrm{AD}$ process (Table 1). Considering the consumption of additional electric energy, we calculated the input electric energy efficiency. As shown in Figure SI4. More than 100\% input electric energy efficiency showed that the additional electric energy was totally covered by the increased methane yield, which implied that a huge potential is required to apply this modification to conventional reactors. Although the input electric energy efficiency always exceeded $100 \%$ during the whole batch operation, the turning point suggested that the strategy of external voltage should be optimized in the future.

\section{MICROBIAL COMMUNITY ANALYSIS}

Microbial Composition. The microbial communities were characterized at the terminal points to compare community structure, diversity, and function in different reactors. Sludge in the MEC-AD showed the highest diversity (Shannon index of 6.17) among six different communities, and the Shannon index of the cathode biofilm was 4.93, which was lower than others (Figures SI5 and SI6). The relative bacterial community abundances were identified on the phylum level, and the main difference among six bacterial communities was attributed to the different distribution of phylum Proteobateria, Bacteroidetes, Firmicutes, and Actinobacteria. Proteobacteria dominated in the original sludge $(50.3 \%)$, which accounted for $13.5 \%$ and $16.7 \%$ in the $\mathrm{AD}$ sludge and MEC-AD sludge, respectively (Figure 3A). At the class level, the main composition of Deltaproteobacteria was Geobacter, which led to higher relative abundance in the anode biofilm (Figure 3B).

To further compare the difference between microbial communities, the distribution of bacteria was identified at genus level. Parabacteroides, Petrimonas, and Proteiniclasticum accounted for $15.0 \%, 10.1 \%$, and $5.1 \%$, respectively, in the $\mathrm{AD}$ sludge that was close to $11.4 \%, 7.3 \%$, and $7.1 \%$ in the MEC-AD sludge (SI7). Petrimonas belonged to fermentative acidic bacteria, and Proteiniclasticum contributed to protein hydrolysis. $^{31}$ The methanogenic community was dominated by Methanosaeta in the sludge with and without electrodes. Visualization of variability in the community composition in both MEC-AD and $\mathrm{AD}$ sludge using principal coordinates analysis (PCoA) indicated that there was no significant difference (Figure SI8). However, the microbial community in the cathode biofilm exhibited a significant difference in the sludge in both reactors. Biofilms of the anode and cathode were highly similar but different from sludge in the $\mathrm{AD}$ and MEC$\mathrm{AD}$ reactor (Figure $3 \mathrm{C}$ ). The number of classified OTUs shared by biofilms on electrodes and sludge in all reactors was 858 , and more than half of the shared OTUs belonged to Proteobacteria (39\%), Firmicutes (24\%), and Bacteroidetes (11\%) (Figure SI9).

The acetogens, Acetobacterium and Acetoanaerobium, were enriched at the cathode (relative abundance of up to $23.1 \%$ and 

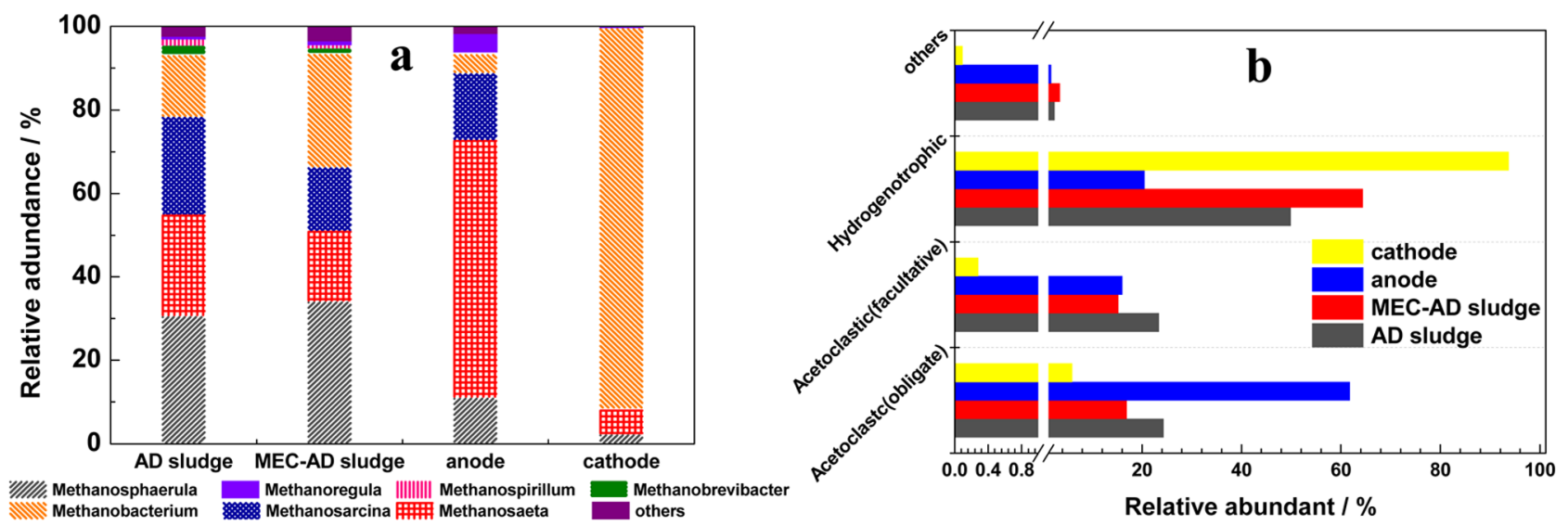

Figure 4. (a) Relative abundance of methanogens. (b) Taxonomy of methanogens and its relative abundance.

$6.3 \%$, relatively) (Figure 3D), and they could play a vital role in hydrogen scavenging and acetic acid synthesizing. ${ }^{37}$ Moreover, Methanosaeta was also detected in the cathode biofilm, where acetate produced by homoacetogens and electrons supplied by electrode supported the growth of Methanosaeta. ${ }^{38}$ The portion of Longilinea and Bellilinea reached $6.82 \%$ and $1.15 \%$, respectively, which ascribed to the enrichment of hydrogentrophic methanogens. ${ }^{39}$

Electrochemically active Geobacter increased from $0.11 \%$ at the anode during startup to $21.86 \%$ on the fifth day, which was in accordance with the increase in Deltaproteobacteria. The relative abundance of Methanosaeta went up to $0.49 \%$ in the anode biofilm compared to $\sim 0.03 \%$ in the startup stage. Acetoanaerobium and Acetobacterium accounted for $4.34 \%$ and $2.50 \%$ in the anode startup, respectively, while the values decreased to $0.33 \%$ and $0.19 \%$ in the anode biofilm.

Methanogens Taxonomy and qPCR Analysis. Among methanogens, Methanobacterium, Methanobrevibacter, Methanoculleus, Methanosphaera, and Methanospirillum were classified into the hydrogenotrophic methanogens, while Methanomethylovorans (facultative), Methanosaeta (obligate), and Methanosarcina (facultative) were acetotrophic methanogens. ${ }^{40}$ Bacteria sequencing results revealed that the cathode biofilm had the highest portion of methanogens, with a relative abundance of $6.99 \%$ for hydrogenotrophic and $0.012 \%$ for acetotrophic. According to the sequencing analysis of archaea separately (Figure $4 \mathrm{a}$ and $\mathrm{b}$ ), Methanobacterium was predominant at the cathode and accounted for $91.08 \%$. Methanosaeta, which was obligate to utilize acetate as substrate for methane production, was enriched at the anode significantly (61.77\%). Furthermore, acetotrophic methanogens (facultative) accounted for $16.01 \%$ at the anode. Hence, the lower relative abundance $(20.49 \%)$ of hydrogenotrophic methanogens was shown. Hydrogenotrophic methanogens accounted for $64.41 \%$ in theMEC-AD sludge, which was slightly higher than that of $\mathrm{AD}$ sludge (49.92\%). Apparently, the ratio of acetoclastic methanogens and hydrogenotrophic methanogens was nearly 1:1 in the sludge phase in both reactors, which revealed similar methanogen distribution in the sludge phase in both reactors. This justified that the introduction of the electrode influenced the methanogenic community slightly. Figure 5 revealed the significant difference in function gene copies of the $m c r A$ gene that encodes the enzyme to catalyze the terminal step in methaongenesis. The number of mcrA in the cathode was obviously higher than in the anode or sludge of $\mathrm{MEC}-\mathrm{AD}$ or $\mathrm{AD}$, indicating methanogens enriched at the cathodic biofilm.

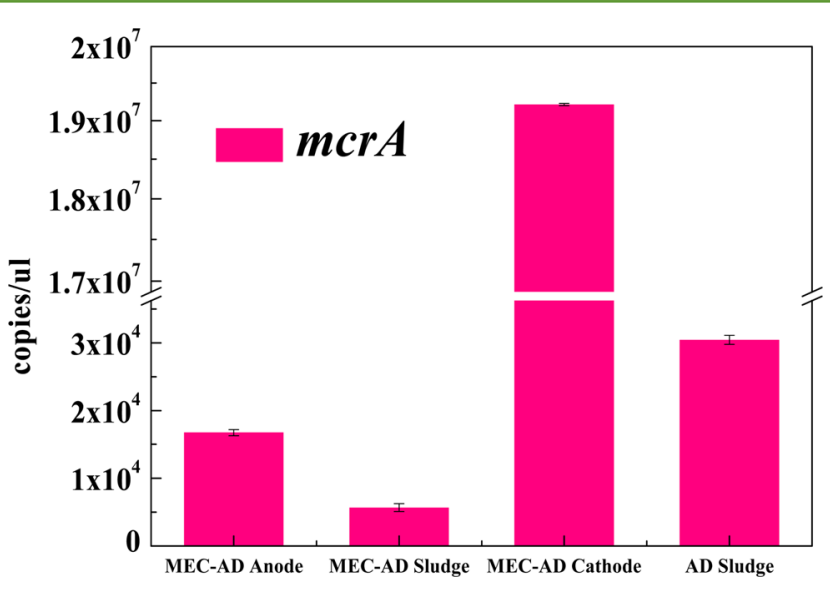

Figure 5. $\mathrm{qPCR}$ analysis of the $m c r A$ abundances in four tested microbial communities.

\section{DISCUSSION}

Bioelectrochemical Contributions to Methane Enhancement in the Hybrid Reactor. Saccharides and proteins directly released from microbial cells after pretreatment resulted in obvious accumulation of VFAs via acidogenesis, which was in accordance to our previous study. ${ }^{31}$ The low accumulation of saccharides and proteins could be ascribed to the utilization of WAS in MEC. ${ }^{20,41}$ Moreover, lower TCOD and VSS removal efficiency of the $\mathrm{AD}$ reactor also represented the positive effect of MEC for substrate degradation. ${ }^{42}$ In addition to effective degradation of complex organics, a nearly 2 -fold increase in the methane production rate with the hybrid reactor was achieved over the $\mathrm{AD}$ reactor. In a previous study, though all electrons contributed to methane, a higher amount of methane was produced from electrochemical regulation, ${ }^{20}$ which was agreeable with the results of this study. Obviously, all methane should be originated from substrate. During the operation period, although fermentation progressed at all times, the VFAs concentration showed a difference in the MEC-AD reactor to $\mathrm{AD}$. Acetate decreased sharply in MEC-AD in the initial days compared to $\mathrm{AD}$, indicating a higher degradation rate caused by the anodic microbial community that competitively consumed acetate for anaerobic respiration. ${ }^{37}$ The initial change in acetate was according to methane generation in MEC-AD. The value of acetate concentration in MEC-AD was significantly lower than that in $\mathrm{AD}$ (single tail, $\mathrm{P}$ value 0.067 ), implying a higher degradation rate of acetate in 
hybrid reactor. The n-butyrate, $\mathrm{n}$-valerate, iso-valerate, and total VFAs value of MEC-AD were significantly lower than that of $\mathrm{AD}(\mathrm{P}=0.030,0.007,0.004$, and 0.057 , respectively $)$. The rest of the VFAs showed a slight difference in the P-value of propionate (0.269) and iso-butyrate (0.370). An obvious accumulation of propionate, n-butyrate, iso-butyrate, and nvalerate occurred at around 20 days in $\mathrm{AD}$ reactor, which slightly happened in MEC-AD. This could be caused by the rapid acetate consumption in MEC-AD; ${ }^{43}$ hence, the negative effect of VFAs accumulation for methane production was relieved in the addition of MEC into $\mathrm{AD}$ process. Furthermore, more than $100 \%$ input electric energy efficiency showed a huge potential to apply this modification to conventional reactor. The additional electric energy was due to the increased methane yield. Hybrid reactor coupling BES and $\mathrm{AD}$ showed remediating capacity and stable energy output in the studies carried out by researchers. $^{23,44}$

Microbial Community Analysis. According to the heat map and PCoA analysis (Figure S7), there was no obvious difference in original communities between $\mathrm{AD}$ and MEC-AD. The main reason for a variety of methane production was caused by the shift in biofilms on the electrodes. The relative higher abundance of Clostridia and Bacteroidia suggested acidogenesis and hydrolysis in the fermentative process. At the anode, the primary role of Geobacter focused on extracellular electron transfer from organics to electrode. With respect to previous studies on the competition between Geobacter and Methanosaeta for the same substrate, acetate would be the most primarily oxidized into electrons and protons by exoelectrogenic bacteria rather than methanogens. ${ }^{45,46}$ Recent finding of direct interspecies electron transfer (DIET) for methane production implied that Methanosaeta were more likely to accept electrons from Geobacter rather than surviving through acetate metabolism. ${ }^{38,47}$ However, methane production from interspecies electron transport did not result in obvious change in methane production rate because of the slow grow rate of Methanosaeta. ${ }^{5}$ Therefore, the shift of microbial community in the cathodic biofilm was of great importance to contribute to the methane production rate increase.

Methane Formation Mechanism within Biocathode Communities. Hydrogen was the main product from endfermentative acids at a high applied voltage ${ }^{29}$ and even fermentative liquid from WAS. ${ }^{48}$ In addition, the electrochemical reduction from $\mathrm{CO}_{2}$ to $\mathrm{CH}_{4}(-0.240 \mathrm{~V}$ vs SHE) with lower potential was easier to occur than the hydrogen evolution $(-0.414 \mathrm{~V}) .^{28}$ Hydrogen was detected during the initial days (5th and 6th day) in closed circuit. However, hydrogenotrophic methanogens and acetogenic bacteria were substantially enriched at the surface of a carbon cloth, resulting in minor detection of hydrogen. Recently, the cathode turned out to be selective for microbial enrichment due to its diverse redox potential. ${ }^{49-51}$ Some new strains at the cathode via microbial electroreduction were isolated, which indicated the selective function of the cathode. ${ }^{52}$ Previous results showed that controlling the redox potential could activate the hydrogenotrophic methanogen $M$. thermautotrophicus at a cathode potential of $-0.850 \mathrm{~V}^{53}$ In this study, potential at the cathode reached $\leftarrow 1.0 \mathrm{~V}$, which was favorable for hydrogen evolution and methanogens growth in the presence of Pt catalyst.

On the basis of the microbial community analysis of the cathode biofilm, Methanobacterium was enriched significantly on the electrode where hydrogen was generated. Methanosaeta accounted for a higher portion at the cathode, and it was related with the enrichment of homoacetogens, which perform the synthesis of acetate from hydrogen and bicarbonate or electrons. As shown in Figure 3D, the following two pathways contributed to the methane production at the cathode of the MEC-AD: (i) Hydrogen that permeated from surface of cathode was utilized by hydrogenotrophic methanogens rapidly. (ii) Acetoclastic methanogens generated methane from acetate that was synthesized from hydrogen or electrons. It was interesting that acetoclastic methanogens were enriched at the cathode, which indicated that the hydrogen evolution not only stimulated the methane formation from hydrogen and carbon dioxide but also acetate synthesis. ${ }^{54}$ The enrichment of hydrogenotrophic methanogens on the cathode resulted in a rapid conversion rate from hydrogen/electrons into methane, indicating a potential strategy for improving methane production rate in $\mathrm{AD}$ process with endogenous hydrogen. Compared with exogenous hydrogen injection, it was advantageous in gas-liquid mass transfer because atomic or molecular hydrogen were favorable for hydrogenotrophic methanogens. ${ }^{53,56}$ In total, the introduction of a microbial electrolysis system in the $\mathrm{AD}$ process showed tremendous potential to regulate the methanogenic community toward a higher methane production rate with a fast growth rate of hydrogenotrophs.

\section{CONCLUSION}

The results of this study indicated that $\mathrm{AD}$ of WAS coupled with the microbial electrolysis process enhanced the methane production rate and process stability, compared with the conventional $\mathrm{AD}$ reactor as the control. According to the results of Illumina MiSeq sequencing, methanogens, especially hydrogenotrophic methanogens Methanobacterium and acetoclastic Methanosaeta, were enriched in the cathode biofilm, and two major pathways of methane production occurred on the cathode surface. The introduction of $\mathrm{MEC}$ into the $\mathrm{AD}$ reactor formed an independent bioelectrochemical section which departs from the $\mathrm{AD}$ section to produce methane effectively. This study suggested a possible approach to reduce WAS digestion time with an increased methane production rate by using microbial electrolysis regulation.

\section{ASSOCIATED CONTENT}

\section{S Supporting Information}

The Supporting Information is available free of charge on the ACS Publications website at DOI: 10.1021/acssuschemeng.6b01221.

Figures S1-S10: S1 (QPCR), S2 (components conversion in MEC-AD and $\mathrm{AD}$ reactor), $\mathrm{S} 3$ (VFAs change in both reactors), S4 (input electric energy efficiency), S5 (alpha diversity), S6 (Shannon index of all samples), S7 (distribution of genus in different samples), S8 (PCoA analysis), S9 (venn diagram), and S10 (accumulative methane production from semicontinuous mode). (PDF)

\section{AUTHOR INFORMATION}

\section{Corresponding Authors}

*E-mail: wzliu@rcees.ac.cn (W. Liu).

*E-mail: waj0578@hit.edu.cn (A. Wang).

Notes

The authors declare no competing financial interest. 


\section{ACKNOWLEDGMENTS}

This research was supported by National Science Foundation for Distinguished Young Scholars (Grant 51225802), National Natural Science Foundation of China (Grants 51208496 and 51578534), Project 135 of Chinese Academy of Sciences (YSW2013B06), and "Hundred Talents Program" of the Chinese Academy of Sciences. The authors appreciate the valuable suggestions, advice, and efforts by Wei-Min $\mathrm{Wu}$, Department of Civil \& Environmental Engineering, Stanford University, in this study.

\section{REFERENCES}

(1) Appels, L.; Baeyens, J.; Degrève, J.; Dewil, R. Principles and potential of the anaerobic digestion of waste-activated sludge. Prog. Energy Combust. Sci. 2008, 34 (6), 755-781.

(2) Nguyen, M. T.; Yasin, N. H. M.; Miyazaki, T.; Maeda, T. Enhancement of sludge reduction and methane production by removing extracellular polymeric substances from waste activated sludge. Chemosphere 2014, 117, 552-558.

(3) Sun, R.; Xing, D.; Jia, J.; Zhou, A.; Zhang, L.; Ren, N. Methane production and microbial community structure for alkaline pretreated waste activated sludge. Bioresour. Technol. 2014, 169, 496-501.

(4) Thauer, R. K.; Kaster, A.-K.; Seedorf, H.; Buckel, W.; Hedderich, R. Methanogenic archaea: ecologically relevant differences in energy conservation. Nat. Rev. Microbiol. 2008, 6 (8), 579-591.

(5) Wu, W.-M.; Jain, M. K.; De Macario, E. C.; Thiele, J. H.; Zeikus, J. G. Microbial composition and characterization of prevalent methanogens and acetogens isolated from syntrophic methanogenic granules. Appl. Microbiol. Biotechnol. 1992, 38 (2), 282-290.

(6) Alphenaar, P. A.; Visser, A.; Lettinga, G. The effect of liquid upward velocity and hydraulic retention time on granulation in UASB reactors treating wastewater with a high sulphate content. Bioresour. Technol. 1993, 43 (3), 249-258.

(7) Bhattacharya, S. K.; Parkin, G. F. The effect of ammonia on methane fermentation processes. Journal (Water Pollution Control Federation) 1989, 55-59.

(8) Borja, R.; Sánchez, E.; Duran, M. Effect of the clay mineral zeolite on ammonia inhibition of anaerobic thermophilic reactors treating cattle manure. J. Environ. Sci. Health, Part A: Toxic/Hazard. Subst. Environ. Eng. 1996, 31 (2), 479-500.

(9) Koster, I.; Lettinga, G. The influence of ammonium-nitrogen on the specific activity of pelletized methanogenic sludge. Agric. Wastes 1984, 9 (3), 205-216.

(10) Robbins, J.; Gerhardt, S.; Kappel, T. Effects of total ammonia on anaerobic digestion and an example of digestor performance from cattle manure-protein mixtures. Biol. Wastes 1989, 27 (1), 1-14.

(11) Sprott, G. D.; Patel, G. B. Ammonia toxicity in pure cultures of methanogenic bacteria. Syst. Appl. Microbiol. 1986, 7 (2), 358-363.

(12) Zeeman, G.; Wiegant, W.; Koster-Treffers, M.; Lettinga, G. The influence of the total-ammonia concentration on the thermophilic digestion of cow manure. Agric. Wastes 1985, 14 (1), 19-35.

(13) Tang, Y.-Q.; Shigematsu, T.; Morimura, S.; Kida, K. Dynamics of the microbial community during continuous methane fermentation in continuously stirred tank reactors. J. Biosci. Bioeng. 2015, 119 (4), $375-383$.

(14) Boe, K.; Angelidaki, I. Online Monitoring and Control of the Biogas Process; Department of Systems BiologyInstitut for Systembiologi, Technical University of Denmark, Danmarks Tekniske Universitet, 2006.

(15) Liese, A.; Seelbach, K.; Wandrey, C. Industrial Biotransformations; John Wiley \& Sons, 2006.

(16) Logan, B. E.; Rabaey, K. Conversion of wastes into bioelectricity and chemicals by using microbial electrochemical technologies. Science 2012, 337 (6095), 686-690.

(17) Pant, D.; Singh, A.; Van Bogaert, G.; Olsen, S. I.; Nigam, P. S.; Diels, L.; Vanbroekhoven, K. Bioelectrochemical systems (BES) for sustainable energy production and product recovery from organic wastes and industrial wastewaters. RSC Adv. 2012, 2 (4), 1248-1263.

(18) Liu, H.; Grot, S.; Logan, B. E. Electrochemically assisted microbial production of hydrogen from acetate. Environ. Sci. Technol. 2005, 39 (11), 4317-4320.

(19) Cheng, S.; Xing, D.; Call, D. F.; Logan, B. E. Direct biological conversion of electrical current into methane by electromethanogenesis. Environ. Sci. Technol. 2009, 43 (10), 3953-3958.

(20) Sasaki, K.; Hirano, S.-i.; Morita, M.; Sasaki, D.; Matsumoto, N.; Ohmura, N.; Igarashi, Y. Bioelectrochemical system accelerates microbial growth and degradation of filter paper. Appl. Microbiol. Biotechnol. 2011, 89 (2), 449-455.

(21) Villano, M.; Monaco, G.; Aulenta, F.; Majone, M. Electrochemically assisted methane production in a biofilm reactor. J. Power Sources 2011, 196 (22), 9467-9472.

(22) Xu, H.; Wang, K.; Holmes, D. E. Bioelectrochemical removal of carbon dioxide ( $\mathrm{CO} 2$ ): an innovative method for biogas upgrading. Bioresour. Technol. 2014, 173, 392-398.

(23) Weld, R. J.; Singh, R. Functional stability of a hybrid anaerobic digester/microbial fuel cell system treating municipal wastewater. Bioresour. Technol. 2011, 102 (2), 842-847.

(24) Guo, X.; Liu, J.; Xiao, B. Bioelectrochemical enhancement of hydrogen and methane production from the anaerobic digestion of sewage sludge in single-chamber membrane-free microbial electrolysis cells. Int. J. Hydrogen Energy 2013, 38 (3), 1342-1347.

(25) Zhou, J.; Liu, W.; Deng, Y.; Jiang, Y. H.; Xue, K.; He, Z.; Van Nostrand, J. D.; Wu, L.; Yang, Y.; Wang, A. Stochastic assembly leads to alternative communities with distinct functions in a bioreactor microbial community. mBio 2013, 4 (2), e00584-12.

(26) Zhang, J.; Zhang, Y.; Quan, X.; Chen, S.; Afzal, S. Enhanced anaerobic digestion of organic contaminants containing diverse microbial population by combined microbial electrolysis cell (MEC) and anaerobic reactor under $\mathrm{Fe}$ (III) reducing conditions. Bioresour. Technol. 2013, 136, 273-280.

(27) $\mathrm{Hu}, \mathrm{H} . ;$ Fan, Y.; Liu, H. Hydrogen production using singlechamber membrane-free microbial electrolysis cells. Water Res. 2008, 42 (15), 4172-4178.

(28) Eerten-Jansen, V.; Mieke, C.; Heijne, A. T.; Buisman, C. J.; Hamelers, H. V. Microbial electrolysis cells for production of methane from CO2: long-term performance and perspectives. Int. J. Energy Res. 2012, 36 (6), 809-819.

(29) Wang, A.; Liu, W.; Cheng, S.; Xing, D.; Zhou, J.; Logan, B. E. Source of methane and methods to control its formation in single chamber microbial electrolysis cells. Int. J. Hydrogen Energy 2009, 34 (9), 3653-3658.

(30) Liu, W.; Huang, S.; Zhou, A.; Zhou, G.; Ren, N.; Wang, A.; Zhuang, G. Hydrogen generation in microbial electrolysis cell feeding with fermentation liquid of waste activated sludge. Int. J. Hydrogen Energy 2012, 37 (18), 13859-13864.

(31) Zhou, A.; Yang, C.; Kong, F.; Liu, D.; Chen, Z.; Ren, N.; Wang, A. Improving the short-chain fatty acids production of waste activated sludge stimulated by a bi-frequency ultrasonic pretreatment. Journal of Environmental Biology 2013, 34 (2 suppl), 381.

(32) Zhou, A.; Yang, C.; Guo, Z.; Hou, Y.; Liu, W.; Wang, A. Volatile fatty acids accumulation and rhamnolipid generation in situ from waste activated sludge fermentation stimulated by external rhamnolipid addition. Biochem. Eng. J. 2013, 77, 240-245.

(33) Zhang, Y.; Cong, J.; Lu, H.; Li, G.; Xue, Y.; Deng, Y.; Li, H.; Zhou, J.; Li, D. Soil bacterial diversity patterns and drivers along an elevational gradient on Shennongiia Mountain, China. Microb. Biotechnol. 2015, 8 (4), 739-46.

(34) Luton, P. E.; Wayne, J. M.; Sharp, R. J.; Riley, P. W. The mcrA gene as an alternative to 16S rRNA in the phylogenetic analysis of methanogen populations in landfillb. Microbiology 2002, 148 (11), $3521-3530$

(35) Stokes, G. B. Estimating the energy content of nutrients. Trends Biochem. Sci. 1988, 13 (11), 422-424. 
(36) Ge, Z.; Li, J.; Xiao, L.; Tong, Y.; He, Z. Recovery of electrical energy in microbial fuel cells: brief review. Environ. Sci. Technol. Lett. 2013, 1 (2), 137-141.

(37) Parameswaran, P.; Zhang, H.; Torres, C. I.; Rittmann, B. E.; Krajmalnik-Brown, R. Microbial community structure in a biofilm anode fed with a fermentable substrate: the significance of hydrogen scavengers. Biotechnol. Bioeng. 2010, 105 (1), 69-78.

(38) Shrestha, P.; et al. A new model for electron flow during anaerobic digestion: direct interspecies electron transfer to Methanosaeta for the reduction of carbon dioxide to methane. Energy Environ. Sci. 2014, 7 (1), 408-415.

(39) Yamada, T.; Imachi, H.; Ohashi, A.; Harada, H.; Hanada, S.; Kamagata, Y.; Sekiguchi, Y. Bellilinea caldifistulae gen. nov., sp. nov. and Longilinea arvoryzae gen. nov., sp. nov., strictly anaerobic, filamentous bacteria of the phylum Chloroflexi isolated from methanogenic propionate-degrading consortia. Int. J. Syst. Evol. Microbiol. 2007, 57 (10), 2299-2306.

(40) Demirel, B.; Scherer, P. The roles of acetotrophic and hydrogenotrophic methanogens during anaerobic conversion of biomass to methane: a review. Rev. Environ. Sci. Bio/Technol. 2008, 7 (2), 173-190.

(41) Lu, L.; Xing, D.; Liu, B.; Ren, N. Enhanced hydrogen production from waste activated sludge by cascade utilization of organic matter in microbial electrolysis cells. Water Res. 2012, 46 (4), $1015-1026$.

(42) Zhang, J.; Zhang, Y.; Quan, X.; Chen, S. Effects of ferric iron on the anaerobic treatment and microbial biodiversity in a coupled microbial electrolysis cell (MEC)-Anaerobic reactor. Water Res. 2013, 47 (15), 5719-5728.

(43) Batstone, D. J.; Pind, P. F.; Angelidaki, I. Kinetics of thermophilic, anaerobic oxidation of straight and branched chain butyrate and valerate. Biotechnol. Bioeng. 2003, 84 (2), 195-204.

(44) De Vrieze, J.; Gildemyn, S.; Arends, J. B.; Vanwonterghem, I.; Verbeken, K.; Boon, N.; Verstraete, W.; Tyson, G. W.; Hennebel, T.; Rabaey, K. Biomass retention on electrodes rather than electrical current enhances stability in anaerobic digestion. Water Res. 2014, 54, 211-221.

(45) Jung, S.; Regan, J. M. Influence of external resistance on electrogenesis, methanogenesis, and anode prokaryotic communities in microbial fuel cells. Applied and environmental microbiology 2011, 77 (2), 564-571.

(46) Kaur, A.; Boghani, H. C.; Michie, I.; Dinsdale, R. M.; Guwy, A. J.; Premier, G. C. Inhibition of methane production in microbial fuel cells: operating strategies which select electrogens over methanogens. Bioresour. Technol. 2014, 173, 75-81.

(47) Richter, H.; Nevin, K. P.; Jia, H.; Lowy, D. A.; Lovley, D. R.; Tender, L. M. Cyclic voltammetry of biofilms of wild type and mutant Geobacter sulfurreducens on fuel cell anodes indicates possible roles of OmcB, OmcZ, type IV pili, and protons in extracellular electron transfer. Energy Environ. Sci. 2009, 2 (5), 506.

(48) Linji, X.; Wenzong, L.; Yining, W.; Aijie, W.; Shuai, L.; Wei, J. Optimizing external voltage for enhanced energy recovery from sludge fermentation liquid in microbial electrolysis cell. Int. J. Hydrogen Energy 2013, 38 (35), 15801-15806.

(49) Liang, B.; Cheng, H.; Van Nostrand, J. D.; Ma, J.; Yu, H.; Kong, D.; Liu, W.; Ren, N.; Wu, L.; Wang, A.; et al. Microbial community structure and function of nitrobenzene reduction biocathode in response to carbon source switchover. Water Res. 2014, 54, 137-148.

(50) Liang, B.; Cheng, H.-Y.; Kong, D.-Y.; Gao, S.-H.; Sun, F.; Cui, D.; Kong, F.-Y.; Zhou, A.-J.; Liu, W.-Z.; Ren, N.-Q.; et al. Accelerated reduction of chlorinated nitroaromatic antibiotic chloramphenicol by biocathode. Environ. Sci. Technol. 2013, 47 (10), 5353-5361.

(51) Wang, A.-J.; Cheng, H.-Y.; Liang, B.; Ren, N.-Q.; Cui, D.; Lin, N.; Kim, B. H.; Rabaey, K. Efficient reduction of nitrobenzene to aniline with a biocatalyzed cathode. Environ. Sci. Technol. 2011, 45 (23), 10186-10193.

(52) de Campos Rodrigues, T.; Rosenbaum, M. A. Microbial electroreduction: screening for new cathodic biocatalysts. ChemElectroChem 2014, 1 (11), 1916-1922.
(53) Hirano, S.; Matsumoto, N.; Morita, M.; Sasaki, K.; Ohmura, N. Electrochemical control of redox potential affects methanogenesis of the hydrogenotrophic methanogen Methanothermobacter thermautotrophicus. Lett. Appl. Microbiol. 2013, 56 (5), 315-321.

(54) Su, M.; Jiang, Y.; Li, D. Production of acetate from carbon dioxide in bioelectrochemical systems based on autotrophic mixed culture. J. Microbiol. Biotechnol. 2013, 23 (8), 1140-1146.

(55) Bassani, I.; Kougias, P. G.; Treu, L.; Angelidaki, I. Biogas upgrading via hydrogenotrophic methanogenesis in two-stage Continuous Stirred Tank Reactors at mesophilic and thermophilic conditions. Environ. Sci. Technol. 2015, 49 (20), 12585-12593.

(56) Guiot, S. R.; Cimpoia, R.; Carayon, G. Potential of wastewatertreating anaerobic granules for biomethanation of synthesis gas. Environ. Sci. Technol. 2011, 45 (5), 2006-2012. 